\title{
A Rare Case of Insecticide Mixture Attempted Homicidal Poisoning Using Cake as a Medium: A Case Report
}

\author{
CHARANSING B. GHOTI*, SHIVANGI S. APTE and MANOJ R. BHANDARKAR
}

Regional Forensic Science Laboratory, Home Department, Government of Maharashtra, Dhantoli, Nagpur-440012, India

charan.ghoti12@gmail.com

Received 23 March 2018 / Accepted 12 April 2018

\begin{abstract}
A 25 years old woman who ate her birthday cake, which was brought by her husband. After consumption of cake she felt some illness like irritation in chest and vomiting, so she was brought to hospital for treatment and doctors collected her gastric lavage during treatment. Chemical analysis of cake sample by thin layer chromatography and Gas chromatography-mass spectroscopy (GC-MS) revealed organophosphorus insecticide chlorpyrifos and pyrethroid insecticide cypermethrin, which confirmed intention of accused to cause health hazard to victim which may lead to homicide.
\end{abstract}

Keywords: Homicidal poisoning, Organophosphorus insecticide, Pyrethroid insecticide, Chlorpyrifos, Cypermethrin, GC-MS

\section{Introduction}

Chlorpyrifos (M.F. $\mathrm{C}_{9} \mathrm{H}_{11} \mathrm{C}_{13} \mathrm{NO}_{3} \mathrm{PS}, O$,O-diethyl O-3,5,6-trichloropyridin-2-yl phosphorothioate) is an organophosphate pesticide; introduced in 1965 by Dow Chemical company ${ }^{1}$. Chlorpyrifos is one of the most widely used organophosphate insecticides in India. It is used in agricultural sector for purpose of killing a number of pests including insects and worms. It acts on the nervous system of insects. Chlorpyrifos is considered moderately hazardous to human reported by $\mathrm{WHO}^{2}$. But high use chlorpyrifos results into poisoning to non-target species like human.

Cypermethrin (M.F. $\mathrm{C}_{22} \mathrm{H}_{19} \mathrm{C}_{2} \mathrm{NO}_{3}$, [cyano-(3-phenoxyphenyl)methyl]3-(2,2-dichloroethenyl)-2,2-dimethylcyclopropane-1-carboxylate) is belonging to pyrethroid class of insecticide that are synthetic esters derived from the naturally occurring toxin pyrethrins, introduced in $1970 \mathrm{~s}^{3}$. It behaves as a fast-acting neurotoxin in insects because it's high insecticidal potential and slow resistance to pest. It is considered less toxic for human use, because of poor dermal absorption, rapid metabolism, less tissue accumulation and environmental persistence. So it is used in many household ant and cockroach killers, 
including raid and ant chalk. Cypermethrin is also used in agriculture to control ectoparasites which infest cattle, sheep and poultry. In veterinary medicine, it is effective at controlling ticks on animals ${ }^{4,5}$.

The trend towards the increased marketing of pesticide mixtures is likely to result in an increase impact of mixed toxicity. Organophosphates and pyrethroids belong to the most often used mixed groups of insecticides in agriculture ${ }^{6}$. These compound are characterized by high insecticidal potency, acute exposure can cause serious adverse effects in humans and other mammals mainly due to neurotoxic action. Exposure to chlorpyrifos and cypermethrin can occur through inhalation, ingestion, eye or skin contact. All routes of exposure can be hazardous, chlorpyrifos and cypermethrin affect on central nervous system (CNS) and respiratory system in humans ${ }^{7}$.

\section{Case history}

A 40 year old lady registered a complaint under IPC 307 against her son in law with alleged intention of poisoning his wife. He brought a cake late night for birthday celebration of his wife. After consuming the cake her daughter felt ill, hence admitted at hospital. Doctor collected gastric lavage during treatment, and investigating officer seized cake from crime scene and sent both samples to forensic laboratory for chemical analysis.

\section{Experimental}

For TLC analysis of Gastric lavage and cake sample were extracted in diethyl ether. The samples were spotted on TLC plates with fine capillary tubes along with pure insecticides as a standard. The plates were dried and developed in a pre-saturated tank containing the solvent system hexane-acetone (8:2, by volume). After developing the plates, the extra solvent was evaporated (dried) in fume hood. The plates were then sprayed with various chromogenic sprays, which are routinely and specifically used for detection of organochloro, organophosphosphate and pyrethroid insecticide.

\section{Gas chromatography-mass spectrometry method}

GC-MS analysis was performed of extract on Agilent 7890B GC equipped with Leco Pegasus HT high throughput TOF MS. Column: RTX-5, Capillary column, Max. Temp. $340{ }^{\circ} \mathrm{C}, 10 \mathrm{~m} \times 180 \mu \mathrm{m} \times 0.20 \mu \mathrm{m}$. Column temperature program: Initial temperature $50{ }^{\circ} \mathrm{C}$ for $1 \mathrm{~min}$ then increased $10{ }^{\circ} \mathrm{C} / \mathrm{min}$ to $280{ }^{\circ} \mathrm{C}$, maintained for $5 \mathrm{~min}$. Run time: $29 \mathrm{~min}$. Injector temperature: $260{ }^{\circ} \mathrm{C}$. Transfer line temperature: $260{ }^{\circ} \mathrm{C}$. Mass range: $45-450 \mathrm{amu}$. Carrier Gas: Helium, Flow Rate: $1.5 \mathrm{~mL} / \mathrm{min}$. Injection mode: Split, Split Ratio: 50.

\section{Results and Discussion}

As per routine forensic toxicological analysis, insecticides are generally analyzed by thinlayer chromatography (TLC), few of chromogenic sprays showed positive response like mercurous nitrate in distilled water, $o$-toludine in acetone and alkali-ferrous sulphate-acid etc., Gastric lavage did not revealed any positive response, whereas chlorpyrifos and cypermethrin were detected by above mentioned spray reagents in cake sample.

For final confirmatory analysis the ether extract was evaporated to dryness and reconstituted with methanol and passed through anhydrous sodium sulphate to remove inorganic phosphate and water content. The methanol extract were filtered with 0.45 micron syringe filter and injected for GC-MS. Gastric lavage does not reveal any peak (Figure 1) while cake extract showed the presence of chlorpyriphos and cypermethrin (Figure 2) in gas 
chromatography. The mass spectrometry shows the same results for the confirmation of chlorpyriphos (Figure 3) and cypermethrin (Figure 4).

This is probably for the first time that the cake extract was found positive for chlorpyriphos and cypermethrin inspite of the impurities and fatty acids in cake, which is referred medico legal case in forensic toxicology.

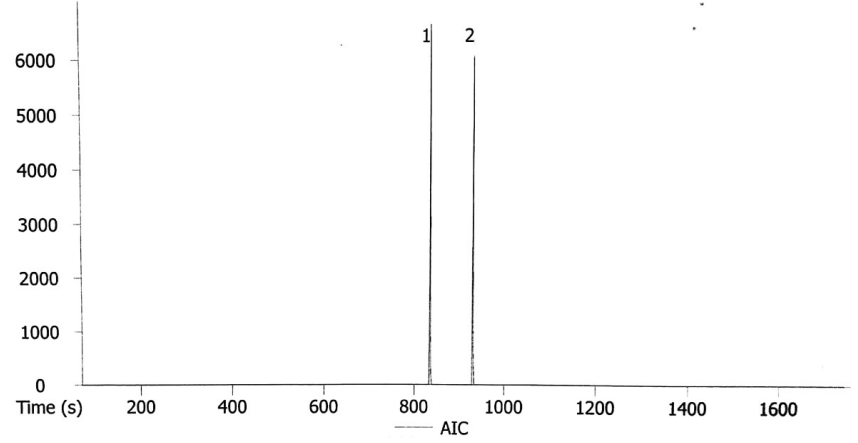

Figure 1. Gas chromatogram of gastric lavage

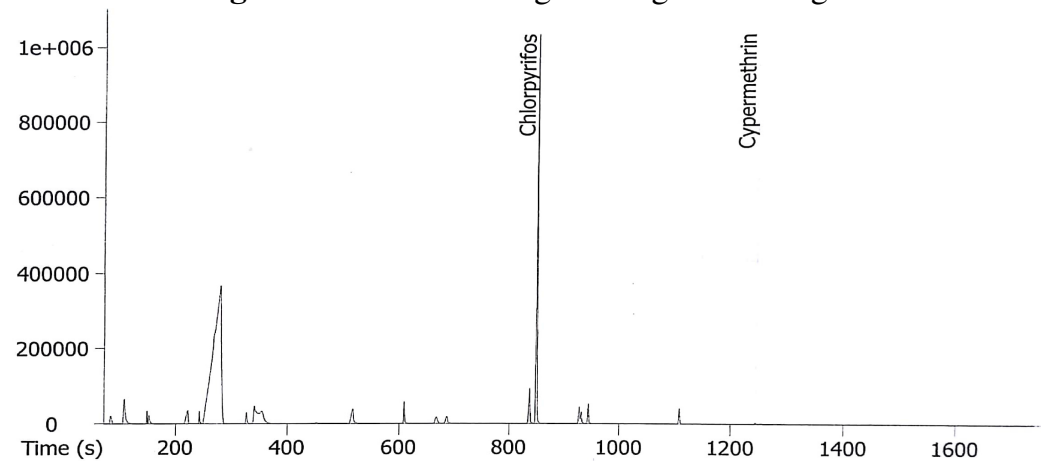

Figure 2. Gas chromatogram of cake sample

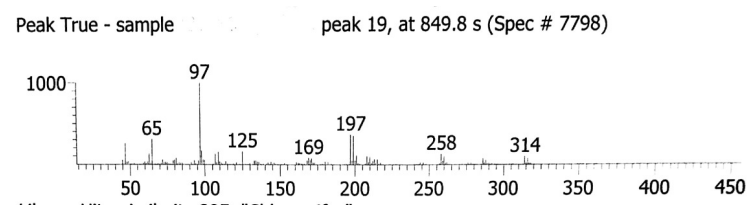

Library Hit - similarity 895, "Chlorpyrifos"
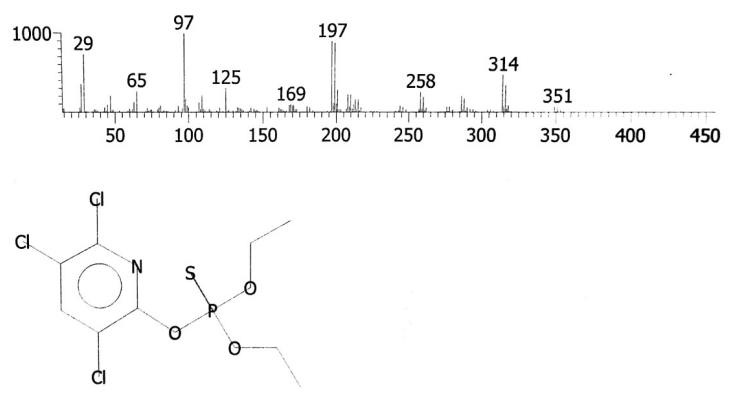

Figure 3. Mass spectrum of chlorpyrifos 


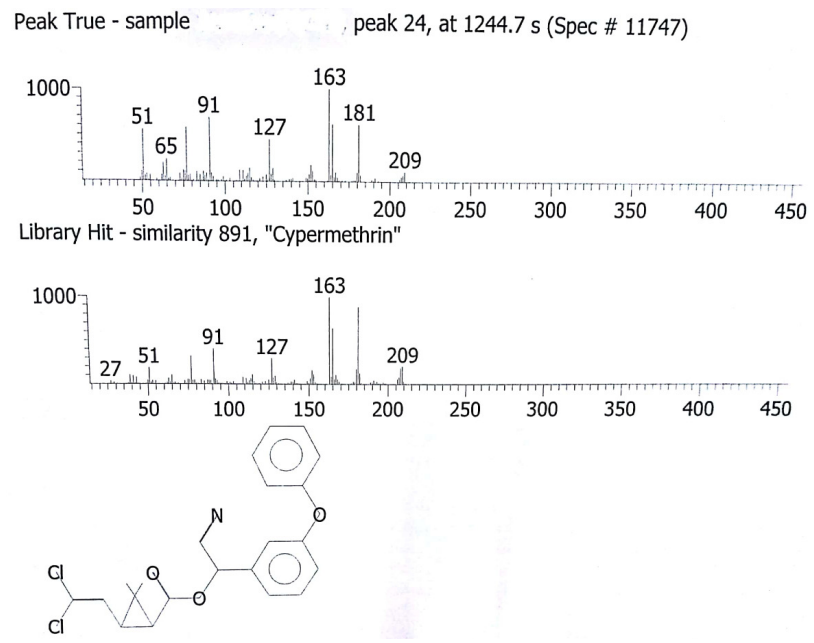

\section{Conclusion}

Figure 4. Mass spectrum of cypermethrin

In India the trend for wide use of pesticide mixtures in agricultural sector increases impact of toxicity. This is probably for the first time that the cake has been used as medium for alleged attempted of homicidal poisoning. Chlorpyrifos and cypermethrin were extracted from cake sample and analysed by gas chromatography-mass spectroscopy. In the present case, Husband of victim has intentionally spiked organophosphorous insecticide chlorpyrifos and pyrethroid insecticide cypermethrin in cake to cause some health hazard to victim, which may have lead to homicide.

\section{Acknowledgement}

The authors wish to thank Dr. K. V. Kulkarni, Director, Directorate of Forensic Science Laboratories, State of Maharashtra, Mumbai, India, for encouraging and supporting us.

\section{References}

1. Rathod A L and Garg R K, J Foren Legal Med., 2017, 47, 29-34; DOI:10.1016/j.jflm.2017.02.003

2. World Health Organization, The WHO Recommended classification of pesticides by hazard and guidelines to classification (Report), 2010, Retrieved on: http://www.who.int/ipcs/publications/pesticides_hazard_2009.pdf

3. Toxicological Profile for Pyrethrins and Pyrethroids , U.S. Department of Health and Human Services, September 2003; Retrieved on: June 2014 http://www.atsdr.cdc.gov/toxprofiles/tp155.pdf

4. Somasani Ayodhya, J Adv Vet Animal Res., 2014, 1(3), 145-147; DOI:10.5455/javar.2014.a18

5. Roger W Stitch, Ectoparasiticides Used in Large Animals, Merck Veterinary Manual; Retrieved on: April, 2018; https://www.merckvetmanual.com/pharmacology/ectoparasiticides/ectopara-siticides-used-in-large-animals.

6. Wielgomas B and Krechniak J, Pol J Environ Stud., 2007, 16(1), 91-95.

7. Liu H, Kan B, Jian X, Zhang W, Zhou Q and Wang J, Exp Ther Med., 2013, 6(3), 696-698; DOI:10.3892/etm.2013.1216 